\title{
Facilitators and barriers to person-centered care in child and young people mental health services: A systematic review.
}

\begin{abstract}
Implementation of person-centered care has been widely advocated across various health settings and patient populations, including recent policy for child and family services. Nonetheless, evidence suggests that service users are rarely involved in decision making, whilst their preferences and goals may be often unheard. The aim of the present research was to systematically review factors influencing person-centered care in mental health services for children, young people and families examining perspectives from professionals, service users, and carers. This was conducted according to best practice guidelines, and seven academic databases were searched. Overall, 23 qualitative studies were included. Findings from the narrative synthesis of the facilitators and barriers are discussed in light of a recently published systematic review examining person-centered care in mental health services for adults. Facilitators and barriers were broadly similar across both settings. Training professionals in person-centered care, supporting them to use it flexibly to meet the unique needs of service users whilst also being responsive to times when it may be less appropriate, and improving both the quantity and quality of information for service users and carers, are key recommendations to facilitate person-centered care in mental health services with children, young people and families.
\end{abstract}


Facilitators and barriers to person-centered care 2

\section{Acknowledgments}

This is an independent report commissioned and funded by the Policy Research Programme in the Department of Health. The views expressed are not necessarily those of the Department. The Child Policy Research Unit (CPRU) is funded by the Department of Health Policy Research Programme. The authors thank the members of CPRU: Terence Stephenson, Catherine Law, Amanda Edwards, Ruth Gilbert, Steve Morris, Helen Roberts, Cathy Street and Russell Viner. 


\section{Background}

Patient- or person-centered care (PCC) was defined by the Health Foundation as care system that "supports us to make informed decisions, helps us to successfully manage our own health and care, and delivers care with respect for our individual abilities, preferences, lifestyles and goals" (Harding, Wait, \& Scrutton, 2015; p. 131). PCC is a multidimensional concept surrounded by an ambiguity regarding its definition, nonetheless there is a consensus that truly person-centered care focusses at its heart on the person, as opposed to the condition or illness, and promotes dignity, respect and compassion (Harding et al., 2015; Leplege et al., 2007; Mead \& Bower, 2000). Due to a wide use of the PCC terminology, there are numerous other interlinked terms, such as 'shared decision making' and 'patient engagement' that reflect fundamental principles of person-centered care and serve as a theoretical guide for this review (Harding et al., 2015).

Implementation of PCC has been widely advocated across various health settings and patient populations, including recent policy for services for children and families, such as Child and Adolescent Mental Health Services (CAMHS; Chief Medical Officer, 2013; Chief Medical Officer, 2014; Department of Health, 2015; Wolpert et al., 2012). Nonetheless, evidence suggests that service users are rarely involved in decision making regarding their care or treatment, and their preferences and goals may be often unheard (Coyne, Hayes, Gallagher, \& Regan, 2006; Wolpert et al., 2012). This can make them feel lonely, ignored, and betrayed (Coyne et al., 2006), which may lead to disengagement from services and treatment. Using an approach grounded in PCC may ameliorate these issues (Simmons, Hetrick, \& Jorm, 2011).

Implementation of PCC in child appears to be more problematic than other healthcare domains as it "raises particular challenges in terms of complex conversations with vulnerable and often highly stressed or disturbed young children, involving on-going and complex 
relationships over time (rather than in a single decision point) and balancing multiple perspectives (e.g., child and parent)" (Wolpert et al., 2012; p. 4). Evidence suggests that service users, their carers, and professionals may differ in perceptions of presenting problems and reasons for attending therapy (Bloemsma et al., 2013; Hawley \& Weisz, 2005; Jepsen, Gray, \& Taffe, 2012; Yeh \& Weisz, 2001), adding to the complexity of implementing PCC. Professionals also raise concerns regarding capacity of service users to be involved in decision-making, due to age and severity of symptoms (Fonagy, Steele, Moran, \& Higgitt, 1991; Ruhe, Wangmo, Badarau, Elger, \& Niggli, 2015). Moreover, involvement of service users in child and young people mental health services may introduce potential safeguarding issues (Abrines-Jaume et al., 2014).

Despite these challenges to implementation, evidence suggests that PCC has a positive impact on self-esteem, self-management, self-efficacy, transitions to adulthood, patient empowerment, and treatment outcomes such as depression, quality of life, and satisfaction (Asarnow et al., 2009; Costello, 2003; Edbrooke-Childs et al., in press; Gyamfi, KeensDouglas, \& Medin, 2007; Joosten, De Jong, de Weert-van Oene, Sensky, \& van der Staak, 2011; Richardson, McCauley, \& Katon, 2009; Westermann, Verheij, Winkens, Verhulst, \& Van Oort, 2013).

Some of the qualitative studies show that service users perceive involvement in treatment decision making as important, emphasizing that they want to be consulted and wellinformed about their illness, to be more engaged in the treatment, and to build a strong therapeutic relationship based on effective communication (Bury, Raval, \& Lyon, 2007; Coyne et al., 2006; Freake, Barley, \& Kent, 2007; Kelsey, Abelson-Mitchell, \& Skirton, 2007). Despite this, studies suggest that service users are often not well informed or involved (Gyamfi et al., 2007; Simmons et al., 2011; Wisdom, Clarke, \& Green, 2006). 
In order to effectively implement PCC, it is necessary to understand the factors that influence it from the perspective of multiple stakeholders. Thus far, there has been only one attempt to systematically review the literature regarding PCC in mental health settings that was conducted in adult services, reporting on factors from the perspective of service users, carers, and healthcare professionals (e.g., psychiatrists, occupational therapists, case managers; Bee, Price, Baker, \& Lovell, 2015). The review included 117 studies conducted across a variety of settings such as community, in-patient, and out-patient mental health services. Factors influencing PCC were distinguished at three levels: relational (i.e. related to the relationship between professionals and service users), individual service users (i.e. capacities and competencies of service users) and organisational (i.e. characteristics of organisational context). In particular, professionals most commonly reported a lack of service users' or carers' interest in and capacity for involvement, administrative burden, a lack of resources, and PCC training and experience (Bee et al., 2015). Conversely, service users and carers most commonly reported professionals' emotional support, respect for service users autonomy, service-level communication failure, and information that was limited in quantity and quality. In addition, power imbalance with professionals was commonly reported. Carers also reported confidentiality as a factor potentially hindering PCC, as it was used by professionals as a reason not to share information leaving carers feeling marginalised (Askey, Holmshaw, Gamblec, \& Grayd, 2009; Bee et al., 2015).

Importantly, the above review was limited to adults in mental health settings. The aim of the present research was to systematically review factors influencing PCC in mental health services for children and young people reported by professionals, service users, and carers.

\section{Methods}

The systematic review was conducted according to the Preferred Reporting Items for Systematic Reviews and Meta-Analyses (Moher, Liberati, Tetzlaff, \& Altman, 2009) and best 
practice guidelines (Centre for Reviews and Dissemination, 2008; Higgins, Green, \& Cochrane Collaboration., 2008). A protocol was developed based on initial scoping of the literature, in which the search strategy was developed by scanning keywords of known papers (e.g., Abrines-Jaume et al., 2014) and search terms of previous related reviews (e.g., Bee et $a l .$, 2015). In addition, the search was refined several times after reviewing initial search results.

The search included four concepts: the population (e.g., child), setting (e.g., mental health), intervention (e.g., person-centered care), and study design (e.g., qualitative) (see Supplementary Table 1 for search terms). As the definition and interpretation of PCC varies extensively (Leplege et al., 2007), a range of terms were used to capture the core elements of PCC as a process and a concept, for instance shared/collaborative decision making, information sharing, or patient participation.

Search terms for each concept were combined using the Boolean operator 'OR', and concepts were combined using the operator 'AND'. The search strategy combined free-text words and Medical Subject Headings (MeSH).

The search was conducted in Ovid MEDLINE, PsycExtra, PsycINFO, Embase, PsycInfo, Web of Science, and the Cumulative Index to Nursing and Allied Health Literature (CINAHL) until $6^{\text {th }}$ November 2015. In addition, reference lists of included publications and other systematic reviews were screened in order to identify any other publications meeting the inclusion criteria. Finally, sources of grey literature (Google Scholar, Open Grey, GreyNet International) were searched.

\section{Inclusion criteria}

Studies were eligible for inclusion based on the criteria shown in Table 1. 
<Insert Table 1 here>

\section{Search flow (see Figure 1 for details)}

The initial search resulted in 8818 hits (Phase 1: Identification). After excluding duplicates, 7676 were identified for the screening of titles/abstracts (Phase 2: Screening). Given the wide variability in definitions of PCC, a 'low threshold' strategy for the Phase 2 screening was employed. Here, full texts were retrieved if the study examined any aspect of service users' utilisation of mental health services (e.g., consent, assessment, treatment) and if any of the reviewers identified the paper as potentially relevant. Given the volume of titles and abstracts, three reviewers carried out filtering in parallel. For the Phase 2, one researcher (LC) screened $80 \%(n=6140)$ titles and abstracts of all publications, whereas the second reviewer $(\mathrm{FS})$ screened $10 \%$ of these $(n=614)$. The agreement between reviewers was very good (Cohen's kappa = 0.88; Landis \& Koch, 1977). In addition, the first author reviewed $20 \%$ of titles and abstracts of all publications $(n=1536)$, whereas the second reviewer (FS) screened $10 \%$ of these $(n=154)$. Again, the agreement between reviewers was high (Cohen`s kappa $=0.91$; Landis \& Koch, 1977). Through the Phase 2 screening, 393 potentially relevant articles were identified. The most common reason for exclusion at this stage was lack of information regarding person-centered care $(n=3624)$. Full texts were retrieved for all papers identified in Phase 2, which were indicated as meeting the inclusion criteria by at least one of the authors. Unpublished or unavailable articles were retrieved with inter-library loans and by contacting the first two authors with two attempts per author. 
At the final stage, the focus was on identifying papers that examined facilitators or barriers to PCC (Phase 3: Eligibility). The eligibility of all retrieved full texts ( $n=523)$ was assessed by the first author (DG), whereas the second reviewer (LC) screened 10\% $(n=52)$ of these chosen at random. The second reviewer also cross-checked full texts that the first reviewer indicated as meeting the inclusion criteria $(n=21)$ and full texts that the first reviewer was not fully confident to exclude $(n=10)$, with very good agreement (Cohen`s kappa $=0.99)$. In the case of disagreement $(n=1)$, a third reviewer $(\mathrm{DH})$ had a decisive opinion. The most common reason for exclusion of the publications was that it did not elaborate on PCC ( $n=332$; see Supplementary Table 2 for the full list of reasons for excluding the publications). Full texts were included if the studies explored views and experiences of PCC as either primary or secondary aims of the study.

The final sample constituted 23 publications, 21 included through the search and additional two identified in the reference lists of relevant publications. 


\section{Data extraction}

Data were extracted from each included study using a data extraction form developed by the authors (TV \& DG) specifically for this review, drawing on best practice guidance (Centre for Reviews and Dissemination, 2008; Higgins et al., 2008). Extracted variables included authors, publication year, aim of the study, study design, type of analysis, setting, sample size, participants, PCC tools or interventions, barriers to PCC, facilitators of PCC, key outcomes, and limitations. Data were extracted from all papers in parallel by two reviewers (DG and FS) for quality checking. Any discrepancies were discussed.

Facilitators and barriers were extracted at any level: (a) patient- and carer-level factors (e.g., motivation, beliefs), (b) professional-level factors (e.g., attitude towards PCC or shareddecision making, motivation), (c) organizational-level (e.g., organizational climate and culture, leadership), and (d) structural and socio-cultural context (e.g., politics, funding, community-level factors). Facilitators and barriers could be reported by professionals (e.g., clinicians), service users, and carers (e.g., parents, legal guardians).

\section{Risk of bias assessment}

The tool for assessing risk of bias in qualitative studies, developed within the Critical Appraisal Skills Programme (Critical Appraisal Skills Programme, 2014), was used. The tool includes 10 criteria (e.g., "Was there a clear statement of the aims of the research?") helping to determine the validity of the studies. The possible responses to nine of the questions are "yes", "no", or "can't tell”. The response should be justified based on the available probes for each question. The final question explores the extent to which the research can be considered as valuable. There are three criteria on which a judgement should be made: 1) if the contribution of the study to existing knowledge (e.g., practice or policy) was discussed, 2) if new areas where research is needed were identified, and 3) how the findings can be used in other populations. In the present review, studies received 1 point for each criterion met, thus 
the value of the research was presented by a score between 0 and 3 . The studies were assessed in parallel by the first author (DG) and the co-author (DH) reaching high agreement (Cohen's kappa = 0.98; Landis \& Koch, 1977); any discrepancies in responses were discussed and a final response option was agreed.

\section{Synthesis of results}

A narrative synthesis (Popay et al., 2006) was used to provide a critical evaluation of evidence on factors affecting provision of PCC in child/youth mental health services, examining the perspective of professionals, service users, and carers. It addition, it examined similarities and differences between these factors as reported by different stakeholders. The presentation of the results and discussion of the findings was commenced with the perspective of the professionals, as it was the dominant narrative in the research.

\section{Results}

\section{Study characteristics}

As shown in Table 2, most studies were conducted in the United Kingdom $(n=10)$, four in the United States of America, five elsewhere in Europe (e.g. Sweden, Ireland). The rest of the studies were carried out in Australia $(n=2)$, Hong Kong $(n=1)$ and Canada $(n=$ 1). In terms of the aims of included studies, eight studies primarily focused on exploring experiences and beliefs related to PCC $(\mathrm{n}=2$; Abrines-Jaume et al., 2014; Grealish, Tai, Hunter, \& Morrison, 2013), whereas other studies looked into various aspects of service users' general experience of mental health services.

Data were collected mainly using semi-structured interviews $(n=11)$, a combination of methods (e.g., interviews and focus groups; $n=7$ ), whereas the analyses used were thematic analysis $(n=9)$, interpretative phenomenological analysis $(n=5)$. Authors of two studies did not report their analytic approach (LeFrançois, 2008; Street, 2004). 
There was a high-level of variation in the study settings, ranging from child/youth mental health services $(n=5)$, other specialised mental health services (e.g., psychiatric clinics, psychiatric emergency services, eating disorders; $n=14$ ), community-based services $(\mathrm{n}=2)$. Finally, authors of two studies used professional registrars to recruit professionals, rather than conducting the study in specific settings (Kovshoff et al., 2012; Tam-Seto \& Versnel, 2015).

The studies reported factors influencing the provision of PCC from the perspective of professionals $(n=6)$, both service users and carers $(n=6)$, professionals and service users $(n$ $=1)$, and carers exclusively $(n=1)$. Notably, in the included studies young person or a child was a primary service user. The sample sizes ranged from 6 to 406 participants. 
<Insert Table 2 here> 


\section{Risk of bias assessment (see Supplementary Table 3)}

The evidence produced in most of the included studies can be deemed as valid and free of serious biases according to the CASP tool (Critical Appraisal Skills Programme, 2014). All studies clearly stated research aims and used the qualitative methodology appropriately, one however did not provide sufficient justification (Molesworth \& Crome, 2011). Finally, all studies but one (Molesworth \& Crome, 2011), presented findings in a comprehensive manner providing quotes illustrating for the main themes obtained by the analysis.

Nonetheless, several studies did not provide sufficient detail on issues such as justification of the research design $(n=3$; Iachini, Hock, Thomas, \& Clone, 2015; Molesworth \& Crome, 2011; Street, 2004), recruitment strategy ( $=$ = 6; Lee et al., 2006; LeFrançois, 2008; Ma \& Lai, 2014; Molesworth \& Crome, 2011; Offord, Turner, \& Cooper, 2006; Street, 2004), data collection ( $\mathrm{n}=3$; LeFrançois, 2008; Molesworth \& Crome, 2011; Street, 2004), the relationship between researcher and participants $(\mathrm{n}=14$; Buckley et al., 2012; Harper, Dickson, \& Bramwell, 2014; Hart, Saunders, \& Thomas, 2005; Iachini et al., 2015; Kovshoff et al., 2012; Lee et al., 2006; LeFrançois, 2008; Molesworth \& Crome, 2011; Offord et al., 2006; Oruche, Downs, Holloway, Draucker, \& Aalsma, 2014; Pelto-Piri, Engstrom, \& Engstrom, 2013; Street, 2004; Tam-Seto \& Versnel, 2015; Wisdom et al., 2006), ethical issues ( $\mathrm{n}=4$; Abrines-Jaume et al., 2014; LeFrançois, 2008; Molesworth \& Crome, 2011; Wisdom et al., 2006), and rigor of data analysis ( $=4$; Hart et al., 2005; LeFrançois, 2008; Molesworth \& Crome, 2011; Street, 2004). Finally, contribution to research, knowledge, or policy was not discussed in two studies (Molesworth \& Crome, 2011; Street, 2004), new areas of research were not identified in six studies (Buckley et al., 2012; Hart et al., 2005; Lee et al., 2006; Molesworth \& Crome, 2011; Pycroft, Wallis, Bigg, \& Webster, 2015; Street, 2004), and generalisability of findings was not taken into account in nine studies (Buckley et 
al., 2012; Bury et al., 2007; Coyne et al., 2015; Kovshoff et al., 2012; LeFrançois, 2008;

Molesworth \& Crome, 2011; Offord et al., 2006; Pelto-Piri et al., 2013; Street, 2004).

Noteworthy, there were three studies that suffered from poor reporting across most items from the CASP tool (Critical Appraisal Skills Programme, 2014), related to recruitment strategy, data collection, or rigor of the analysis (LeFrançois, 2008; Molesworth \& Crome, 2011; Street, 2004). Moreover, one study used open-ended survey questions to explore experiences of youth receiving mental health services, which appeared to be a highly flawed data collection method (Lee et al., 2006). Thus, findings from these studies should be treated with caution. 
<Insert Table 3 here> 


\section{Factors influencing PCC (see Table 3)}

\section{Professional-level factors.}

One of the most prominent factors coded at the professional-level that was reported by professionals, service users, and carers was lack of sharing information regarding treatment. This was predominantly described as being a barrier to PCC (Buckley et al., 2012; Coyne et al., 2015; Hart et al., 2005; Iachini et al., 2015; Ma \& Lai, 2014; Simmons et al., 2011; Simmons, Hetrick, \& Jorm, 2013; Street, 2004; Wisdom et al., 2006), however it was reported to be a facilitator when it did occur (Buckley et al., 2012; Bury et al., 2007; Iachini et al., 2015; Ma \& Lai, 2014; Simmons et al., 2011). Equally valued as a factor influencing PCC was when service users and carers were listened to and their opinions respected and validated. When this occurred it was perceived as a facilitator to PCC and was reported from studies examining healthcare professionals, young people, and carers perspectives (Grealish et al., 2013; Hart et al., 2005; Iachini et al., 2015; Idenfors, Kullgren, \& Salander Renberg, 2015; Offord et al., 2006; Pelto-Piri et al., 2013; Pycroft et al., 2015; Simmons et al., 2011; Wisdom et al., 2006) but as barriers when they did not (Buckley et al., 2012; Coyne et al., 2015; Grealish et al., 2013; Wisdom et al., 2006).

Professionals reported apprehension to changing practice due to potential safeguarding concerns and also feeling "clunky" or unskilled in how to involve service users in decisionmaking (Abrines-Jaume et al., 2014). Similarly, professionals reported a tension over service users' age/ capacity and PCC (LeFrançois, 2008; also see service user-/ carer-level factors; Simmons et al., 2013). Another barrier related to age was a reluctance to discuss sexual side effects of medication with service users (Simmons et al., 2013). Challenges in first aligning views amongst a multi-disciplinary team were mentioned by professionals as being a barrier to then involving service users in care delivery (Simmons et al., 2013). In addition, service 
users reported the disparity in expertise with professionals, in terms of language (Grealish et al., 2013) and a lack of specialist knowledge (Harper et al., 2014), as a barrier to PCC.

In contrast, being flexible in their approach and trusting young people to be involved were reported by professionals as facilitators to PCC and overcoming the aforementioned barriers (Abrines-Jaume et al., 2014; Kovshoff et al., 2012; Molesworth \& Crome, 2011). It was also acknowledged by professionals, service users, and carers that additional effort "going that extra mile" - is necessary to ensure that PCC is implemented (Abrines-Jaume et al., 2014; Buckley et al., 2012; Oruche et al., 2014).

\section{Relationship-level factors}

The importance of the quality of the relationship between professionals and services as well as support from professionals for service users and carers was consistently mentioned as a key factor influencing PCC, which can be attributed as a facilitator to PCC (Buckley et al., 2012; Coyne et al., 2015; Grealish et al., 2013; Lee et al., 2006; Oruche et al., 2014; PeltoPiri et al., 2013; Pycroft et al., 2015; Tam-Seto \& Versnel, 2015; Wisdom et al., 2006) but also a barrier when relationships and support were poor (Buckley et al., 2012; Oruche et al., 2014; Tam-Seto \& Versnel, 2015). According to service users, communication between professionals and service users was an important determinant of a high quality relationship, thus its presence was cited as a facilitator to PCC (Grealish et al., 2013; Lee et al., 2006; Pycroft et al., 2015), whereas absence of communication was a barrier to PCC (Lee et al., 2006; Simmons et al., 2011). Finally, power imbalance between service users and professionals (Bury et al., 2007; Harper et al., 2014) and a lack of continuity in relationships, resulting in service users seeing a number of different professionals, were reported as being barriers to PCC (Harper et al., 2014). 


\section{Service user-/ carer-level factors}

Service users' capacity to be involved in decision-making, due to age and severity of symptoms, and concerns about confidentiality were raised as key barriers to PCC by professionals, service users, and carers (Idenfors et al., 2015; LeFrançois, 2008; Oruche et al., 2014; Simmons et al., 2011, 2013; Tam-Seto \& Versnel, 2015; Wisdom et al., 2006). However, only professionals cited that capacity to consent to treatment is determined by age not the stage of development, which not only has ethical and legal implications but may also cause concerns if for instance, age and developmental stage are not aligned (also see servicelevel factors; Simmons et al., 2013). In addition, although service users may occasionally not be able to fully participate in decision making with PCC, they advocated their greater involvement at times when it was appropriate (LeFrançois, 2008; Tam-Seto \& Versnel, 2015).

Parental involvement was reported to be a factor influencing PCC according to professionals, service users, and carers (Grealish et al., 2013; Harper et al., 2014; Iachini et al., 2015; Kovshoff et al., 2012; Oruche et al., 2014; Tam-Seto \& Versnel, 2015). Service users trusted carers to act as surrogates for PCC to make decisions on their behalf when they were particularly unwell (Grealish et al., 2013) and in general they felt more supported when a parent or relative was involved (Iachini et al., 2015; Kovshoff et al., 2012; Tam-Seto \& Versnel, 2015). Involving carers in treatment appeared to benefit both service users and carers themselves and it was promoted by both these groups, as well as professionals (Oruche et al., 2014). Carers reported having a better understanding of the illness and they felt better equipped to manage the illness (Oruche et al., 2014). 
Nonetheless, parental involvement was not exclusively described in positive terms, as it was reported as being overly intrusive at times (Harper et al., 2014). Service users felt that parents were seen as the primary "service user", reducing the young person's role in PCC. Presence of parents during the session also contributed to self-censorship, where both service users and carers felt "inhibited to speak in from of each other" (Coyne et al., 2015; p. 565). When service users had a choice of seeing professionals without carers, in services for 16-18 year-olds, this mitigated the potential barrier of parental over-involvement (Harper et al., 2014). Service users described PCC as becoming easier as they matured into young adults and developed skills and confidence for self-expression (Harper et al., 2014).

Professionals mentioned that service users' preconceptions about mental health (e.g., stigma) and previous experiences with mental health service (e.g., a lack of PCC) may be a barrier to service users' engagement with a service and, in turn, PCC (Simmons et al., 2013; p. 11). Similarly, service users reported that a strong desire to appear "normal" might also prevent PCC as service users may deny their diagnoses and minimize symptoms to both themselves and professionals (Wisdom et al., 2006).

\section{Service-level factors}

Professionals, service users, and carers reported limited resources (e.g., staff, time) and a lack of information in age appropriate language/ materials as barriers to PCC (Buckley et al., 2012; Ma \& Lai, 2014; Oruche et al., 2014; Pelto-Piri et al., 2013; Pycroft et al., 2015; Simmons et al., 2011; Street, 2004). Treatment options were also considered by professionals and service users to be limited (Lee et al., 2006; Simmons et al., 2013).

Extensive policies and regulations were seen by professionals and service users as a barrier to PCC as they were inflexible and often prevented the provision of individualised treatment based on service users` needs (Idenfors et al., 2015; Pelto-Piri et al., 2013; TamSeto \& Versnel, 2015). Similarly, having a rigid structure to treatment provision, based on 
pre-conceived plans, could be a barrier to PCC according to service users, nonetheless a complete lack of structure was also undesirable (Tam-Seto \& Versnel, 2015). Service users described a lack of flexibility for professionals to depart from a service's operating procedures as resulting in service users feeling they had no choice and autonomy (Grealish et al., 2013; Offord et al., 2006; Pelto-Piri et al., 2013; Wisdom et al., 2006). Inflexibility in treatment provision was also attributed by professionals to the fact that treatment decisions were often made before service users were seen (e.g., by other professionals in the assessment team, by the General Practice), which was ultimately seen as barriers to PCC (Simmons et al., 2013).

In order to mitigate challenges related to the application of PCC, professionals encouraged nurturing a collaborative team culture, since multi-disciplinary working amongst the team then trickled through to encouraging PCC with service users (Simmons et al., 2013).

Service users highlighted an importance of providing parents with continued support, particularly when service users were unwell, as not being able to access any help would leave their carers feeling unsupported and isolated (Grealish et al., 2013). As indicated by carers, such support could also be provided by other community-based services, however it is necessary that the primary mental health providers are aware of the availability of these services (Iachini et al., 2015).

Carers also reported a lack of information as a barrier to PCC, but this was mainly due to confidentiality policies, which meant that information could not be shared with a carer as the young person was over a certain age, even if this did not necessarily reflect their developmental stage (Simmons et al., 2011). Finally, carers emphasised that mental health professionals should be culturally competent to provide PCC, as cultural background may have a strong impact on perception of service users and their carers (Iachini et al., 2015).

\section{Context-level factors}


The two factors coded at the context-level were barriers related to lack of resources regarding youth mental health reported by professionals. Professionals reported that a lack of research evidence with the populations they see (e.g., about medications) prevented them from in turn sharing evidence and information with service users (Simmons et al., 2013). Professionals in Australia reported that funding restrictions meant that not only were service users offered a limited number of sessions, but appointments with carers were not subsidized; hence, service users had to miss school to attend sessions even if the focus of work was with the carer, which also consequently resulted in less available sessions for work focusing on the young person (Simmons et al., 2013).

\section{Discussion}

Due to an increasing focus on care provided in mental health services according to a person-centered approach, the aim of the present research was to systematically review factors influencing PCC in mental health services for children and young people as reported by professionals, service users, and carers. This review is particularly needed as previous reviews focused on physical health settings (Gravel, Legare, \& Graham, 2006; Legare, Ratte, Gravel, \& Graham, 2008), and the only such review conducted in mental health settings included exclusively adult populations (Bee et al., 2015). Interestingly, we found similar facilitators and barriers to PCC in child/youth mental health as reported in adult mental health, which suggests that key recommendations may help improve PCC across both settings.

Findings of the present research, in line with the previous review (Bee et al., 2015), suggest that there is an urgent need to improve the information provision for service users and carers within mental health services, as this was one of the most predominant barriers to PCC reported by service users in child/youth and adult services. Information should be shared in a language that is jargon-free and comprehensible for service users and carers in order to 
redress the perceived power imbalance with professionals reported by service users in both child and adult settings (Bee et al., 2015; Bury et al., 2007; Harper et al., 2014). Providing information co-produced by service users for example, may be vital in tackling this barrier (Bee et al., 2015; Simmons et al., 2013; Street, 2004). It is also essential there is a sufficient level of communication between professionals and service users in order to facilitate information provision as well as to nurture positive relationships; this was also seen as an important factor affecting PCC in both child/youth and adult services (Bee et al., 2015; Grealish et al., 2013; Lee et al., 2006; Pycroft et al., 2015; Simmons et al., 2011).

Effective PCC also requires confidence and knowledge from professionals, which can be attained by training and opportunities to develop practical experience of working within a PCC framework. As demonstrated in both reviews, professionals in both settings reported a lack of expertise in involving service users in care and decision making (Abrines-Jaume et al., 2014; Bee et al., 2015). A collaborative practice may need to be encouraged not only between professionals and service users but also across services and multi-disciplinary teams to avoid communication breakdowns or disagreements in terms of treatment provision (Bee $e t$ al., 2015; Simmons et al., 2013).

Service users in both child/youth and adult mental health settings expressed concerns over their capacity to be involved in decision making during a crisis, but at other times were keen to be actively involved in care (Bee et al., 2015; Simmons et al., 2011; Wisdom et al., 2006). Nonetheless, professionals working across both populations tended to underestimate participants' capacity or willingness to participate in decision-making about their care (Bee et al., 2015; LeFrançois, 2008; Simmons et al., 2013; Tam-Seto \& Versnel, 2015). Irrespective of whether the setting is child or adult mental health, professionals may need to make additional effort to approach PCC in an innovative manner responding to the unique needs of 
service users (Abrines-Jaume et al., 2014; Bee et al., 2015; Buckley et al., 2012; LeFrançois, 2008; Oruche et al., 2014).

At the service level, professionals, service users, and carers reported a lack of resources and extensive policy regulations as key barriers to PCC, that reduce the flexibility with which professionals can provide treatment aiming to address individual needs of the service users (Buckley et al., 2012; Grealish et al., 2013; Idenfors et al., 2015; Ma \& Lai, 2014; Oruche et al., 2014; Pelto-Piri et al., 2013; Pycroft et al., 2015; Simmons et al., 2011, 2013; Street, 2004).

The key differences between child/youth and adult mental health services were seen at the service user/carer level. The role of carer in the context of child/youth mental health provision was particularly complex, as widely elaborated by professionals, service users and carers, which was not a prominent factor influencing PCC in adult care (Bee et al., 2015). Despite the fact that carers were in general supportive and their involvement was sought after by children/young people, they also tended to be described as overly intrusive by service users leaving them feeling excluded from playing a central role in their treatment (Harper $e t$ $a l .$, 2014). Moreover, children/young people appeared to be more likely to refrain from sharing their experience in an open manner in the presence of carers, whereas carers felt isolated if they were not receiving detailed information about the treatment, even if that was due to confidentiality regulations (Bee et al., 2015; Coyne et al., 2015). Thus, professionals in child/youth mental health services ought to draw a close attention to the delicate balance between service users autonomy and parental involvement whilst reassuring service users about confidentiality of the information they share. This is particularly important until young people develop confidence in expressing themselves within the services, which may take place when they become adolescents (Harper et al., 2014). 
This research was conducted and reported according to the best practice guidelines (Centre for Reviews and Dissemination, 2008; Higgins et al., 2008; Moher et al., 2009). We conducted a thorough search in seven academic databases, sources of grey literature and we scanned reference lists of relevant publications. Although we employed a wide theoretical framework in defining PCC, due to a varied use of the term, we have no assurance that we have captured all relevant studies as PCC, for instance from countries with differing conceptualisation of PCC. Thus, future research would benefit from a scoping review of theories of PCC helping to clarify what constitutes PCC, particularly in the context of child/youth mental health services that would lead the way for the development of theorydriven interventions to promote PCC. Furthermore, the current review focused exclusively on qualitative studies, hence future systematic reviews should examine quantitative evidence of PCC to examine the effectiveness of PCC. Finally, in the current study we were interested in the perspective of young person/child as a service user. Nonetheless, gaining insight into the views of parents or the entire family as service users, for instance within family-centered approach, would further add to our understanding of facilitators and barriers to PCC.

The findings of the present research suggest some key recommendations to facilitate PCC. Improving the information provision for service users and carers, in terms of its quality and quantity, and communicating it in easily-understandable fashion is urgently needed. In addition, a greater focus should be put on the role of relationships in the process of PCC provision. Professionals should also receive further support, in the form of training in PCC, to improve their confidence and knowledge, allowing them the opportunity to develop practical experience of working within a PCC framework. Similarly, professionals should be supported to use PCC in a flexible manner to ensure it meets the unique needs of service users and is responsive to times when PCC may be less appropriate, such as during crisis. Drawing on similar reviews from adult mental health services (Bee et al., 2015), these recommendations 
may help to facilitate PCC in mental services across settings for a range of professionals, services users, and carers.

Our review demonstrates that despite a current drive for PCC in child/youth mental health settings with a strong input from service users and their carers, the care provided is still far from being implemented according to PCC principles (Department of Health, 2015). Partial responsibility for this may lie with increasing bureaucracy in services and growing emphasis on a performance culture that limits the resources and flexibility in providing truly PCC (Innes, Macpherson, \& McCabe, 2006). In order to diminish impact of these challenges, commissioners and service providers must be committed to developing workforce characterised by an ability and willingness to listen to, trust and believe in children`s/young people`s capacity to be involved in care, whilst providing a choice of interventions and sufficient information (Department of Health, 2015). 
Facilitators and barriers to person-centered care 26

\section{References}

Abrines-Jaume, N., Midgley, N., Hopkins, K., Hoffman, J., Martin, K., Law, D., \& Wolpert, M. (2014). A qualitative analysis of implementing shared decision making in Child and Adolescent Mental Health Services in the United Kingdom: Stages and facilitators. Clinical Child Psychology and Psychiatry. doi: 10.1177/1359104514547596

Asarnow, J. R., Jaycox, L. H., Tang, L., Duan, N., LaBorde, A. P., Zeledon, L. R., . . Wells, K. B. (2009). Long-term benefits of short-term quality improvement interventions for depressed youths in primary care. American Journal of Psychiatry, 166(9), 1002-1010. doi: 10.1176/appi.ajp.2009.08121909

Askey, R., Holmshaw, J., Gamblec, C., \& Grayd, R. (2009). What do carers of people with psychosis need from mental health services? Exploring the views of carers, service users and professionals. Journal of Family Therapy, 31, 310-331.

Bee, P., Price, O., Baker, J., \& Lovell, K. (2015). Systematic synthesis of barriers and facilitators to service user-led care planning. British Journal of Psychiatry, 207(2), 104-114. doi: 10.1192/bjp.bp.114.152447

Bloemsma, J. M., Boer, F., Arnold, R., Banaschewski, T., Faraone, S. V., Buitelaar, J. K., . . Oosterlaan, J. (2013). Comorbid anxiety and neurocognitive dysfunctions in children with ADHD. European Child and Adolescent Psychiatry, 22(4), 225-234. doi: 10.1007/s00787-012-0339-9

Buckley, S., Gavin, B., Noctor, C., Devitt, C., Guerin, S., \& Team, T. W. F. P. (2012). Mental health services: the way forward. The perspectives of young people and parents. Dublin: St Patrick's University Hospital.

Bury, C., Raval, H., \& Lyon, L. (2007). Young people's experiences of individual psychoanalytic psychotherapy. Psychol Psychother, 80(Pt 1), 79-96. doi: 10.1348/147608306X109654

Centre for Reviews and Dissemination. (2008). Systematic reviews: CRD's guidance for undertaking reviews in health care. York: CRD, University of York.

Chief Medical Officer. (2013). Annual report of the Chief Medical Officer 2012. Our children deserve better: Prevention pays. London: Department of Health.

Chief Medical Officer. (2014). Annual report of the Chief Medical Officer 2013. Public mental health priorities: investing in the evidence. London: Department of Health.

Costello, J. C. (2003). "The trouble is they're growing, the trouble is they're grown": Therapeutic jurisprudence and adolescents' participation in mental health care decisions. Ohio Northern University Law Review, 29(3), 607-640.

Coyne, I., McNamara, N., Healy, M., Gower, C., Sarkar, M., \& McNicholas, F. (2015). Adolescents' and parents' views of child and adolescent mental health services (CAMHS) in Ireland. Journal of Psychiatric and Mental Health Nursing, 22(8), 561-569. doi: 10.1111/jpm.12215

Coyne, I. T., Hayes, E., Gallagher, P., \& Regan, G. (2006). Giving children a voice: Investigation of children's experiences of participation in consultation and decision-making in Irish hospitals. Dublin: Office of the Minister for Children.

Critical Appraisal Skills Programme. (2014). CASP Checklists. Oxford: CASP.

Department of Health. (2015). Future in mind: promoting, protecting and improving our children and young people's mental health and wellbeing. London: Department of Health.

Edbrooke-Childs, J., Bradley, J., Argent, R., Patalay, P., Deighton, J., \& Wolpert, M. (in press). The relationship between child- and parent-reported shared decision making and child-, parent-, and clinician-reported outcome in routinely collected child mental health services data. Clinical Child Psychology and Psychiatry. doi: 10.1177/1359104515591226

Fonagy, P., Steele, M., Moran, G. S., \& Higgitt, A. C. (1991). The capacity for understanding mental states: The reflective self in parent and child and its significance for security of attachment. Infant Mental Health Journal, 12, 201-218.

Freake, H., Barley, V., \& Kent, G. (2007). Adolescents' views of helping professionals: a review of the literature. Journal of Adolescence, 30(4), 639-653. doi: 10.1016/j.adolescence.2006.06.001 
Gravel, K., Legare, F., \& Graham, I. D. (2006). Barriers and facilitators to implementing shared decision-making in clinical practice: a systematic review of health professionals' perceptions. Implement Science, 1, 16. doi: 10.1186/1748-5908-1-16

Grealish, A., Tai, S., Hunter, A., \& Morrison, A. P. (2013). Qualitative exploration of empowerment from the perspective of young people with psychosis. Clinical Psychology and Psychotherapy, 20(2), 136-148. doi: 10.1002/cpp.785

Gyamfi, P., Keens-Douglas, A., \& Medin, E. (2007). Youth and youth coordinators' perspectives on youth involvement in systems of care. The Journal of Behavioral Health Services \& Research, 34(4), 382-394. doi: 10.1007/s11414-007-9068-0

Harding, E., Wait, S., \& Scrutton, J. (2015). The state of play in person-centred care: A pragmatic review of how person-centred care is defined, applied and measured. London: The Health Policy Partnership.

Harper, B., Dickson, J. M., \& Bramwell, R. (2014). Experiences of young people in a 16-18 mental health service. Child and Adolescent Mental Health, 19(2), 90-96.

Hart, A., Saunders, A., \& Thomas, H. (2005). Attuned practice: a service user study of specialist child and adolescent mental health, UK. Epidemiol Psichiatr Soc, 14(1), 22-31.

Hawley, K. M., \& Weisz, J. R. (2005). Youth versus parent working alliance in usual clinical care: distinctive associations with retention, satisfaction, and treatment outcome. Journal of Clinical Child \& Adolescent Psychology, 34(1), 117-128. doi: 10.1207/s15374424jccp3401_11

Higgins, J. P. T., Green, S., \& Cochrane Collaboration. (2008). Cochrane handbook for systematic reviews of interventions. Chichester, England; Hoboken, NJ: Wiley-Blackwell.

Iachini, A. L., Hock, R. M., Thomas, M., \& Clone, S. (2015). Exploring the youth and parent perspective on practitioner behaviors that promote treatment engagement. Journal of Family Social Work, 18(1), 57-73. doi: 10.1080/10522158.2014.974293

Idenfors, H., Kullgren, G., \& Salander Renberg, E. (2015). Professional care after deliberate self-harm: a qualitative study of young people's experiences. Patient Prefer Adherence, 9, 199-207. doi: 10.2147/PPA.S76244

Innes, A., Macpherson, S., \& McCabe, L. (2006). Promoting person-centred care at the front line. York: Joseph Rowntree Foundation.

Jepsen, M. I., Gray, K. M., \& Taffe, J. R. (2012). Agreement in multi-informant assessment of behaviour and emotional problems and social functioning in adolescents with autistic and Asperger's disorder. Research in Autism Spectrum Disorders, 6, 1091-1098. doi: 10.1016/j.rasd.2012.02.008

Joosten, E. A., De Jong, C. A., de Weert-van Oene, G. H., Sensky, T., \& van der Staak, C. P. (2011). Shared decision-making: increases autonomy in substance-dependent patients. Substance Use and Misuse, 46(8), 1037-1038. doi: 10.3109/10826084.2011.552931

Kelsey, J., Abelson-Mitchell, N., \& Skirton, H. (2007). Perceptions of young people about decision making in the acute healthcare environment. Paediatric Nursing, 19(6), 14-18.

Kovshoff, H., Williams, S., Vrijens, M., Danckaerts, M., Thompson, M., Yardley, L., . . Sonuga-Barke, E. J. S. (2012). The decisions regarding ADHD management (DRAMa) study: uncertainties and complexities in assessment, diagnosis and treatment, from the clinician's point of view. European Child \& Adolescent Psychiatry, 21(2), 87-99. doi: 10.1007/s00787-011-0235-8

Landis, J. R., \& Koch, G. G. (1977). The measurement of observer agreement for categorical data. Biometrics, 33(1), 159-174.

Lee, B. R., Munson, M. R., Ware, N. C., Ollie, M. T., Scott, L. D. J., \& McMillen, J. C. (2006). Experiences of and attitudes toward mental health services among older youths in foster care. Psychiatric Services, 57(4), 487-492.

LeFrançois, B. A. (2008). "It's like mental torture": Participation and mental health services. International Journal of Children's Rights, 16, 211-227. doi: DOI 10.1163/157181808X301809 
Legare, F., Ratte, S., Gravel, K., \& Graham, I. D. (2008). Barriers and facilitators to implementing shared decision-making in clinical practice: update of a systematic review of health professionals' perceptions. Patient Educ Couns, 73(3), 526-535. doi: 10.1016/j.pec.2008.07.018

Leplege, A., Gzil, F., Cammelli, M., Lefeve, C., Pachoud, B., \& Ville, I. (2007). Person-centredness: conceptual and historical perspectives. Disabil Rehabil, 29(20-21), 1555-1565. doi: 10.1080/09638280701618661

Ma, J. L. C., \& Lai, K. Y. C. (2014). Family engagement in children with mental health needs in a Chinese context: A dream or reality? Journal of Ethnic \& Cultural Diversity in Social Work: Innovation in Theory, Research \& Practice, 23(3-4), 173-189. doi: 10.1080/15313204.2013.838815

Mead, N., \& Bower, P. (2000). Patient-centredness: a conceptual framework and review of the empirical literature. Social Science \& Medicine, 51(7), 1087-1110. doi: 10.1016/S02779536(00)00098-8

Moher, D., Liberati, A., Tetzlaff, J., \& Altman, D. G. (2009). Preferred reporting items for systematic reviews and meta-analyses: the PRISMA statement. BMJ, 339, b2535. doi: 10.1136/bmj.b2535

Molesworth, S., \& Crome, I. (2011). What is so special about young people? Views from practitioners. Mental Health and Substance Use, 4(1), 83-92.

Offord, A., Turner, H., \& Cooper, M. (2006). Adolescent inpatient treatment for anorexia nervosa: A qualitative study exploring young adults' retrospective views of treatment and discharge. European Eating Disorders Review, 14(6), 377-387. doi: 10.1002/erv.687

Oruche, U. M., Downs, S., Holloway, E., Draucker, C., \& Aalsma, M. (2014). Barriers and facilitators to treatment participation by adolescents in a community mental health clinic. J Psychiatr Ment Health Nurs, 21(3), 241-248. doi: 10.1111/jpm.12076

Pelto-Piri, V., Engstrom, K., \& Engstrom, I. (2013). Paternalism, autonomy and reciprocity: ethical perspectives in encounters with patients in psychiatric in-patient care. BMC Med Ethics, 14, 49. doi: 10.1186/1472-6939-14-49

Popay, J., Roberts, H., Sowden, A., Petticrew, M., Arai, L., Rodgers, M., . . Duffy, S. (2006). Guidance on the conduct of narrative synthesis in systematic reviews: Final report. London: ESRC Methods Programme.

Pycroft, A., Wallis, A., Bigg, J., \& Webster, G. (2015). Participation, engagement and change: A study of the experiences of service users of the unified adolescent team. British Journal of Social Work, 1-18. doi: 10.1093/bjsw/bct089

Richardson, L., McCauley, E., \& Katon, W. (2009). Collaborative care for adolescent depression: a pilot study. General Hospital Psychiatry, 31(1), 36-45. doi:

10.1016/j.genhosppsych.2008.09.019

Ruhe, K. M., Wangmo, T., Badarau, D. O., Elger, B. S., \& Niggli, F. (2015). Decision-making capacity of children and adolescents - suggestions for advancing the concept's implementation in pediatric healthcare. European Journal of Pediatrics, 174(6), 775-782. doi: 10.1007/s00431014-2462-8

Simmons, M. B., Hetrick, S. E., \& Jorm, A. F. (2011). Experiences of treatment decision making for young people diagnosed with depressive disorders: a qualitative study in primary care and specialist mental health settings. BMC Psychiatry, 11, 194. doi: 10.1186/1471-244X-11-194

Simmons, M. B., Hetrick, S. E., \& Jorm, A. F. (2013). Making decisions about treatment for young people diagnosed with depressive disorders: a qualitative study of clinicians' experiences. BMC Psychiatry, 13(335), 13-335.

Street, C. (2004). In-patient mental health services for young people - changing to meet new needs? Perspectives in Public Health, 124(3), 115-118. 
Tam-Seto, L., \& Versnel, J. (2015). Occupational therapy shared decision making in adolescent mental health. Occupational Therapy in Mental Health, 31(2), 168-186. doi: 10.1080/0164212X.2015.1036194

Westermann, G. M., Verheij, F., Winkens, B., Verhulst, F. C., \& Van Oort, F. V. (2013). Structured shared decision-making using dialogue and visualization: a randomized controlled trial. Patient Education and Counseling, 90(1), 74-81. doi: 10.1016/j.pec.2012.09.014

Wisdom, J. P., Clarke, G. N., \& Green, C. A. (2006). What teens want: barriers to seeking care for depression. Administration and Policy in Mental Health and Mental Health Services Research, 33(2), 133-145. doi: 10.1007/s10488-006-0036-4

Wolpert, M., Hoffman, J., Abrines, N., Feltham, A., Baird, L., Law, D., .. Hopkins, K. (2012). Closing the gap through changing relationships. Final report for closing the gap through changing relationships. London, England: The Health Foundation.

Yeh, M., \& Weisz, J. R. (2001). Why are we here at the clinic? Parent-child (dis)agreement on referral problems at outpatient treatment entry. Journal of Consulting and Clinical Psychology, 69(6), 1018-1025. 
Table 2

Characteristics of included studies.

\begin{tabular}{|c|c|}
\hline $\begin{array}{l}\text { Reference } \\
\text { and country }\end{array}$ & Aim \\
\hline $\begin{array}{l}\text { Grealish et } \\
\text { al. (2011) }\end{array}$ & $\begin{array}{l}\text { To qualitatively conceptualize } \\
\text { empowerment from the perspective of } \\
\text { young people experiencing psychosis. }\end{array}$ \\
\hline $\begin{array}{l}\text { UK } \\
\text { Harper et } \\
\text { al. (2014) }\end{array}$ & $\begin{array}{l}\text { To gain understanding of young people's } \\
\text { experiences of mental health services. }\end{array}$ \\
\hline $\begin{array}{l}\text { UK } \\
\text { Hart et al. } \\
\text { (2005) }\end{array}$ & $\begin{array}{l}\text { To explore some of the complexities } \\
\text { inherent in children's services when } \\
\text { parents are integral to modes of treatment. }\end{array}$ \\
\hline
\end{tabular}

Iachini et al. To explore the perspective of youth and (2015) parents regarding practitioner behaviors USA important for fostering treatment engagement.
Idenfors et To explore young people's perceptions of al. (2015) care and support during a 6-month period following their first contact for deliberate Sweden

\begin{tabular}{|c|c|c|}
\hline $\begin{array}{c}\text { Methodology } \\
\text { of data } \\
\text { collection }\end{array}$ & Analysis & $\begin{array}{l}\text { Participants (N; age; } \\
\text { profession/diagnosis) }\end{array}$ \\
\hline $\begin{array}{c}\text { Semi- } \\
\text { structured } \\
\text { interviews }\end{array}$ & IPA & $\begin{array}{l}\text { Young people }(N=9 ; 14 \text { to } \\
\text { years; diagnosed with } \\
\text { schizophrenia spectrum } \\
\text { disorders) }\end{array}$ \\
\hline $\begin{array}{c}\text { Semi- } \\
\text { structured } \\
\text { interviews }\end{array}$ & IPA & $\begin{array}{l}\text { Young people ( } N=10 ; 16 \text { tc } \\
18 \text { years; diagnosed with lor } \\
\text { mood, low mood/self-harm, } \\
\text { anxiety, anxiety/low mood) }\end{array}$ \\
\hline $\begin{array}{l}\text { Interviews } \\
\text { Focus groups }\end{array}$ & Thematic analysis & $\begin{array}{l}\text { Young people }(N=27 ; 11-1 \\
\text { years; depression, school } \\
\text { behavioural difficulties, } \\
\text { ADHD, self-harm, family } \\
\text { breakdown) }\end{array}$ \\
\hline $\begin{array}{c}\text { Semi- } \\
\text { structured } \\
\text { interviews }\end{array}$ & $\begin{array}{l}\text { Grounded theory } \\
\text { (constant } \\
\text { comparative } \\
\text { analysis) }\end{array}$ & $\begin{array}{l}\text { Carers }(N=39 ; \text { age ?) } \\
\text { Young people }(N=19 ; 15.2 \\
\text { years; diagnosis ?) }\end{array}$ \\
\hline
\end{tabular}

Semistructured interviews

\section{Content analysis}

Young people $(N=9 ; 16-24$ years; treated due to deliberate self-harm)

\section{Setting}

\section{CAMHS}

16-18 MHS in the National Health Service

\section{CAMHS}

Group and individual therapy providers, various mental healthrelated services (special education, residential care, juvenile justice, substance abuse treatment)

Emergency department, child and adolescent psychiatry. 
Table 2

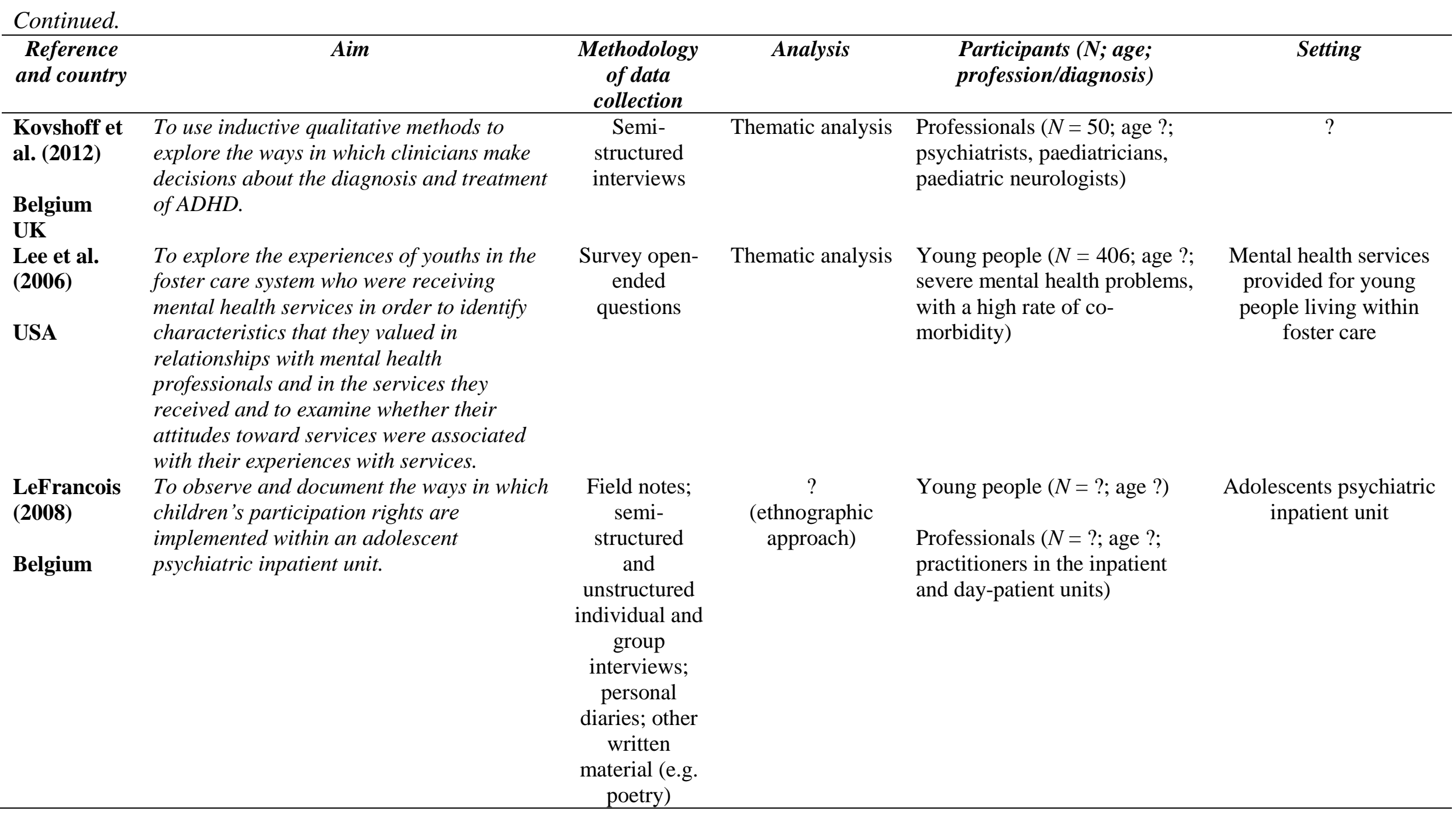


Table 2

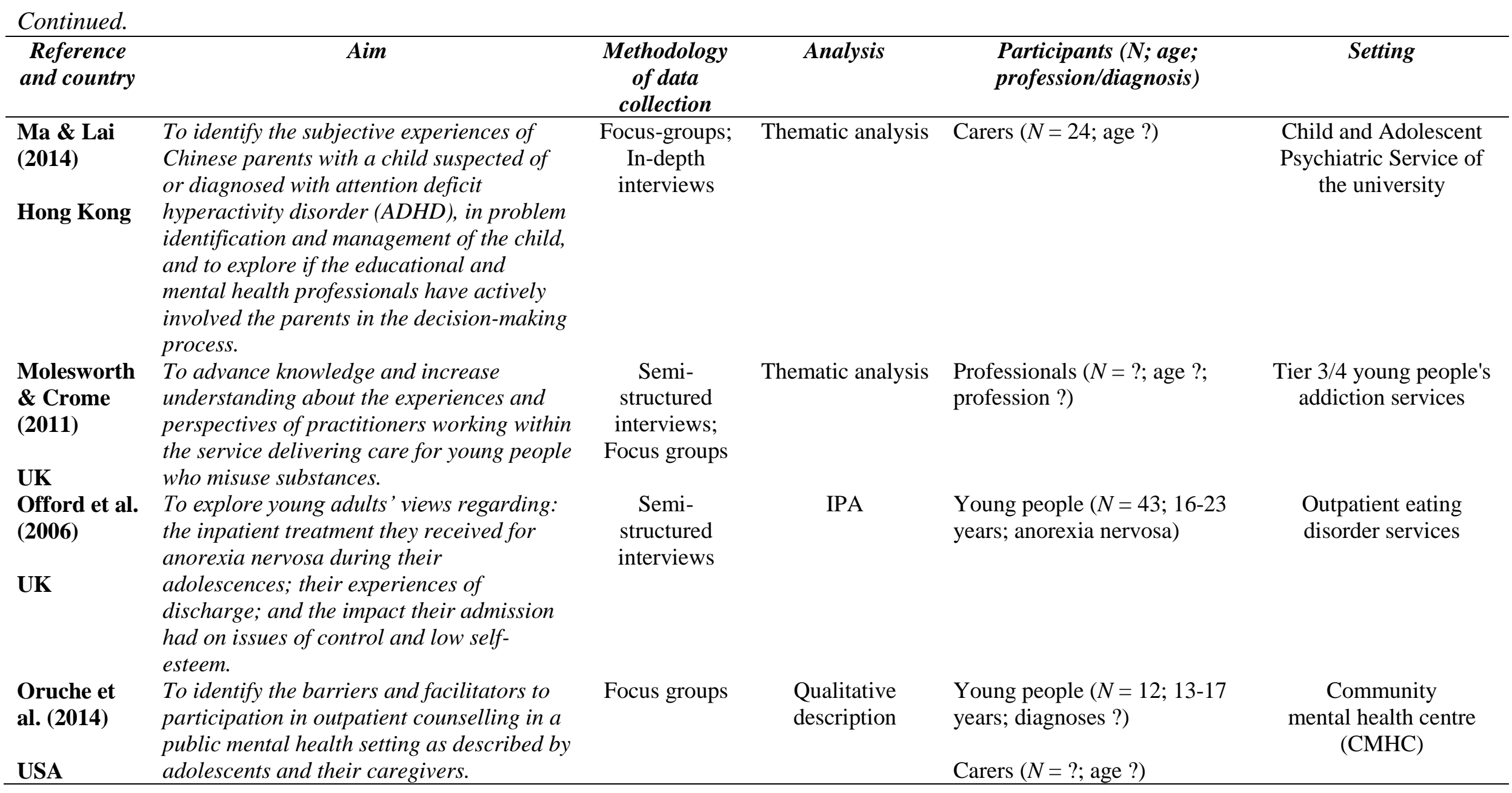


Table 2

\begin{tabular}{|c|c|c|c|c|c|}
\hline $\begin{array}{l}\text { Pelto-Piri et } \\
\text { al. (2013) } \\
\text { Sweden }\end{array}$ & $\begin{array}{l}\text { To describe and analyse statements } \\
\text { describing real work situations and ethical } \\
\text { reflections made by staff members in } \\
\text { relation to three central perspectives in } \\
\text { medical ethics; paternalism, autonomy and } \\
\text { reciprocity. }\end{array}$ & Ethical diaries & Content analysis & $\begin{array}{l}\text { Professionals }(N=173 ; 44 \\
\text { years; registered nurses, } \\
\text { psychiatrists, psychologists, } \\
\text { social workers, teachers })\end{array}$ & $\begin{array}{l}\text { Psychiatric clinics for } \\
\text { adults } \\
\text { child and adolescent } \\
\text { psychiatric clinics }\end{array}$ \\
\hline $\begin{array}{l}\text { Simmons et } \\
\text { al. (2011) } \\
\text { Australia }\end{array}$ & $\begin{array}{l}\text { To explore the experiences and desires of } \\
\text { young people and their caregivers in } \\
\text { relation to being involved in treatment } \\
\text { decision making for depressive disorders. }\end{array}$ & $\begin{array}{c}\text { Semi- } \\
\text { structured } \\
\text { interviews }\end{array}$ & Thematic analysis & $\begin{array}{l}\text { Young people }(N=10 ; 15-24 \\
\text { years; diagnosed with } \\
\text { depressive disorders) } \\
\text { Carers ( } N=? ; 40-55 \text { years) }\end{array}$ & $\begin{array}{c}\text { Orygen Youth Health } \dagger \\
\text { Barwon } \dagger \dagger\end{array}$ \\
\hline
\end{tabular}


Table 2

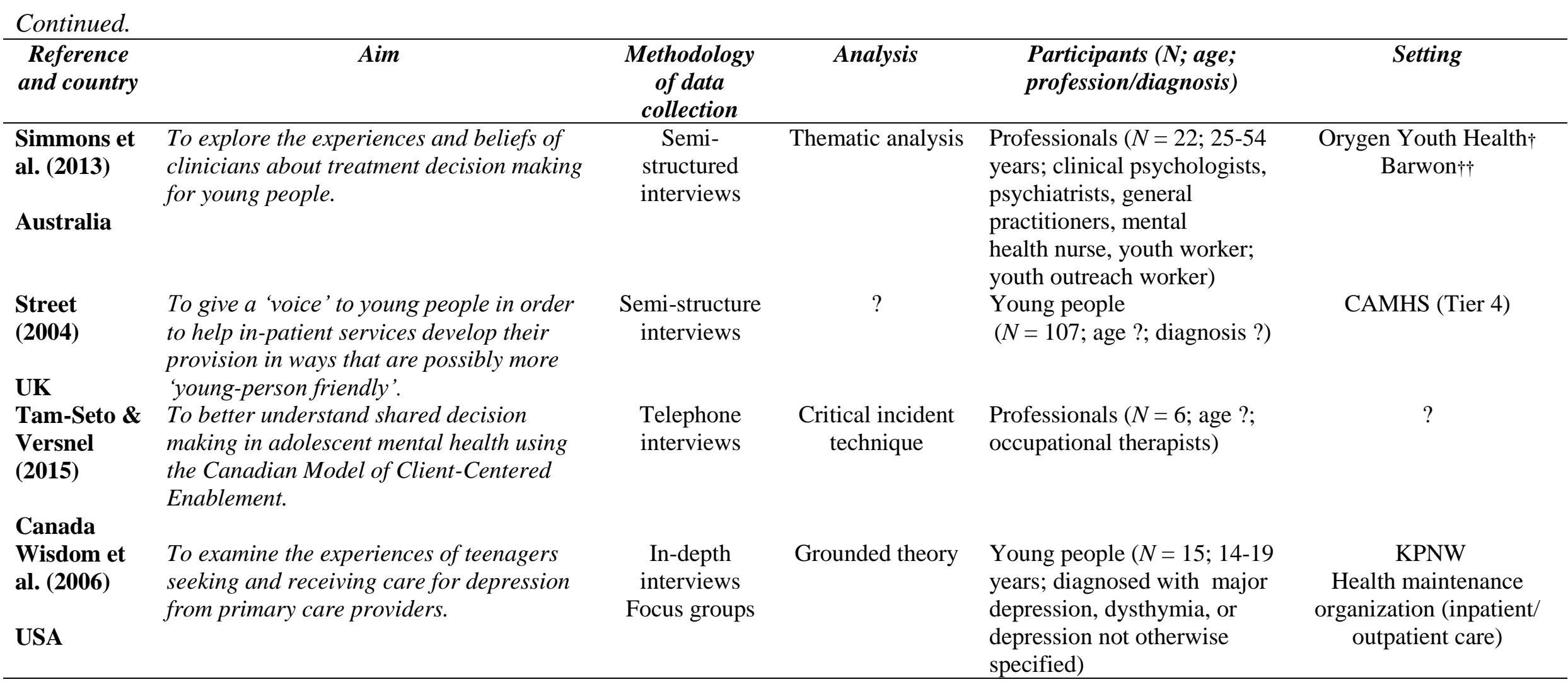

Note . CAMHS = Child and Adolescent Mental Health Services; $?=$ unspecified/unknown; IPA = Interpretative Phenomenological Analysis; MHS = Mental health services; $\mathrm{ADHD}=$ Attention deficit hyperactivity disorder; KPNW $=$ Kaiser Permanente Northwest.

$\uparrow$ A specialist youth mental health service for young people aged 15-24.

$\dagger \dagger$ An enhanced general practice service for young people aged 12-25. 
Table 3

Facilitators and barriers to PCC.

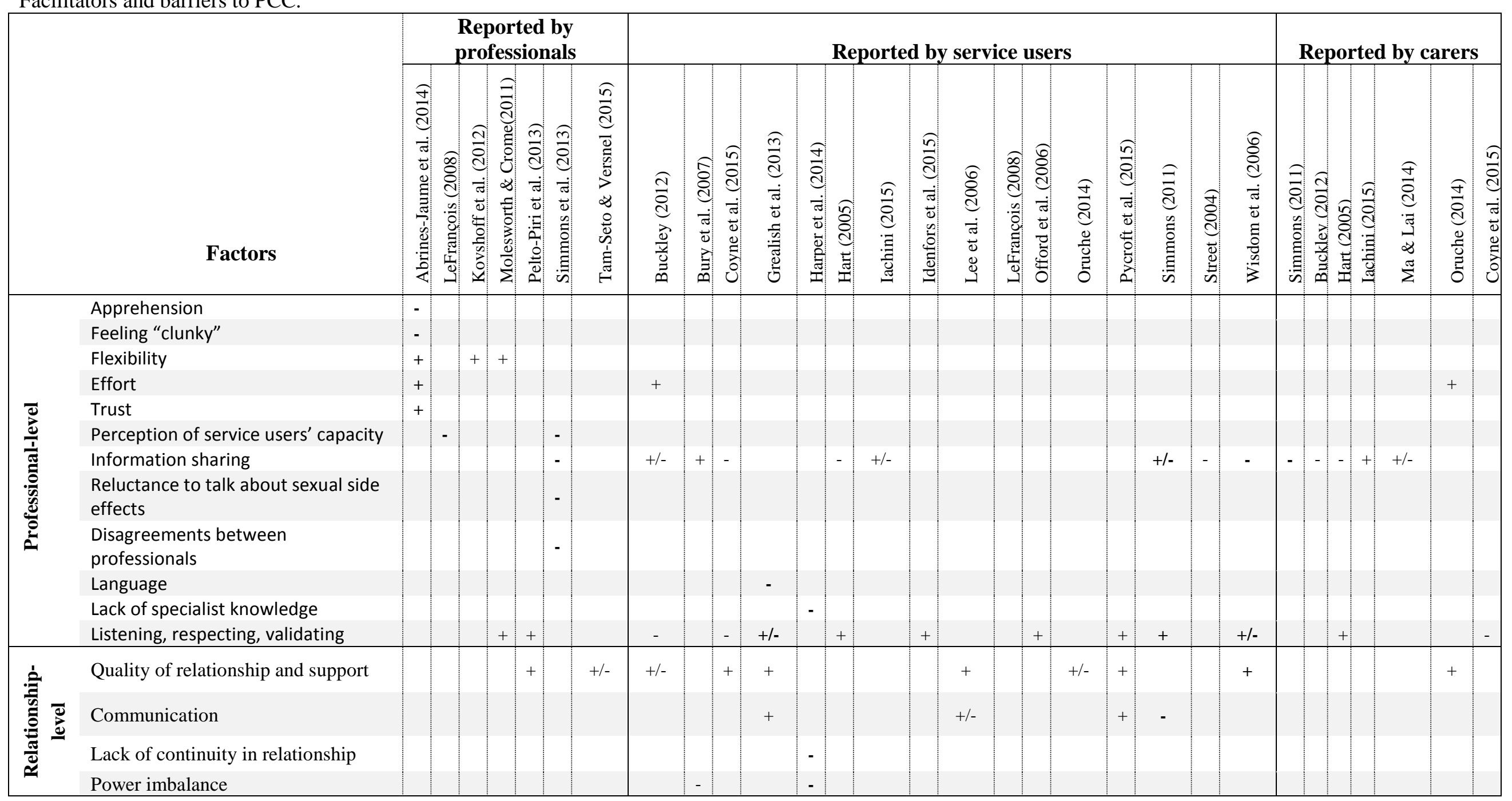


Table 3

Continued.

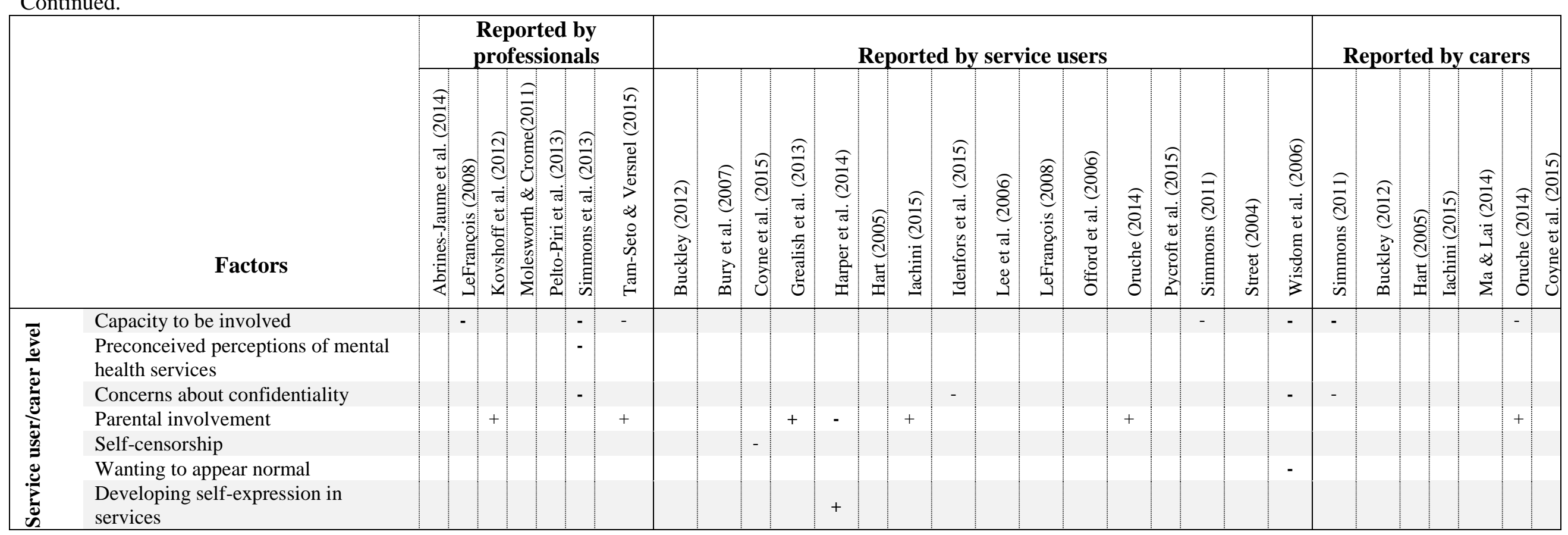


Table 3

Continued

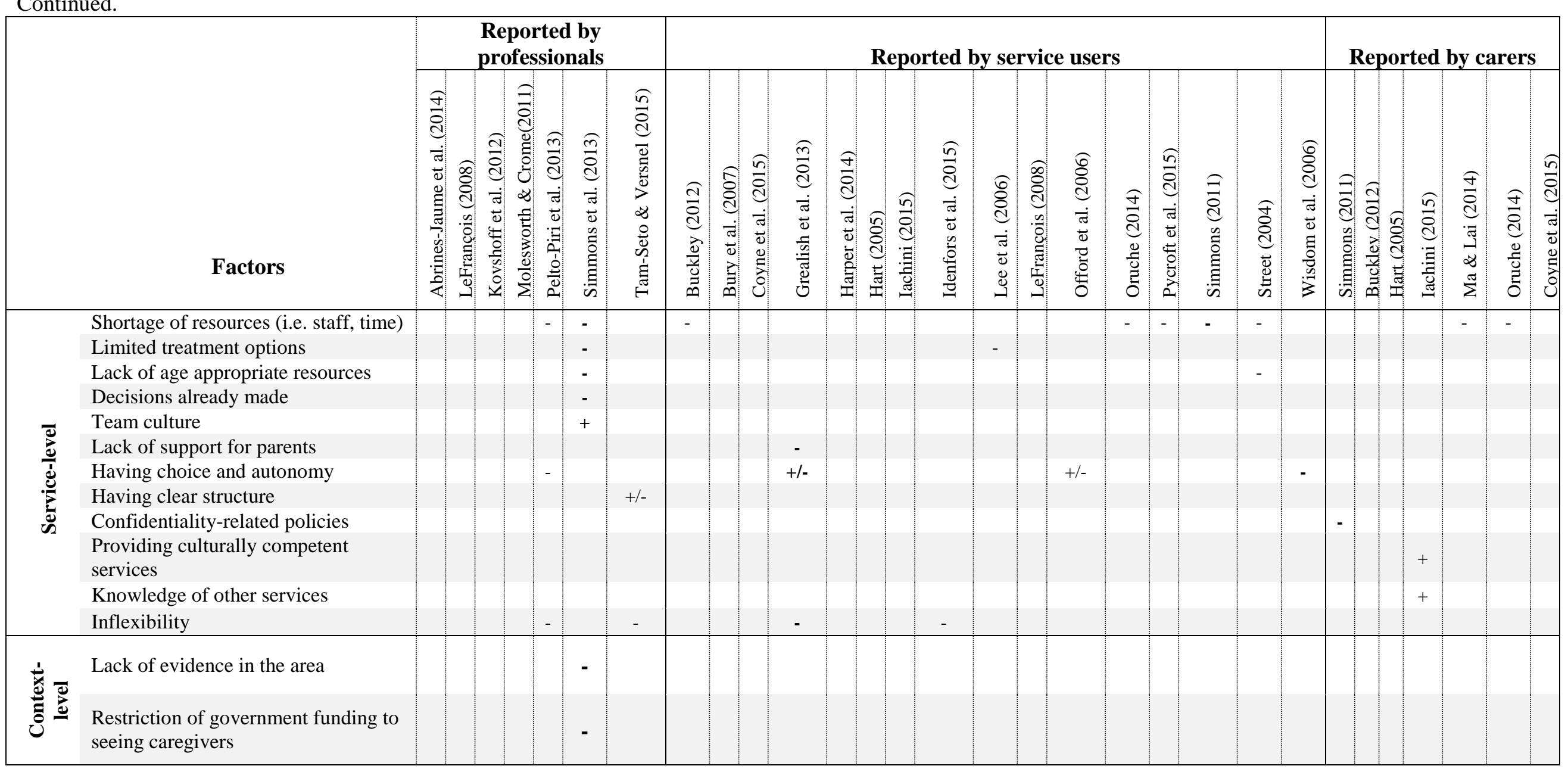

Note. "+" = facilitator; "_“= barrier; "+/_" = indicated both as a facilitator and barrier. 
Appendix 1

Supplementary Table 1.

Search conducted within each database with resulting hits (after exclusion of duplicates).

Database Timespan Number of hits Search terms

\begin{tabular}{lll}
\hline Ovid MEDLINE(R) & 1946 to October Week 52015 & 440 \\
PsycEXTRA & 1908 to November 02, 2015 & 83 \\
PsycINFO & 1806 to November Week 1 2015 & 1172 \\
Embase & 1974 to 2015 Week 44 & 1381
\end{tabular}

440

83 1974 to 2015 Week 44 (collaborati* or consultation* or cooperation or involvement or partnership or shar* decision or decision making or SDM or information sharing or patient participation or decision aid or informed choice or person cent* or person focus* or patient cent* or patient focus* or decision support or patient activation or shar* model or patient preference or patient activation or decision theory or patient relation or professional-patient relations or physician-patient relations or doctor-patient relations or patient involv* or

participation).ti,ab,sh,kw. AND (child* or adolesc* or young or youth or teen*).ti,ab,sh,kw. AND (mental health or mental health service or mental illness or mental disorder or mental difficult* or mentally ill or psychiatr*).ti,ab,sh,kw. AND (qualitative or ethnograph* or phenomenolog* or content analysis or thematic analysis or constant comparative method or interview or focus group or case study or grounded theory or narrative or interpretive phenomenological).ti,ab,md.

\begin{tabular}{|c|c|c|c|}
\hline $\begin{array}{l}\text { EBSCO host } \\
\text { (CINAHL Plus) }\end{array}$ & All years & 619 & $\begin{array}{l}\text { ((collaborati* or consultation* or cooperation or involvement or partnership or shar* } \\
\text { decision or decision making or SDM or information sharing or patient participation or } \\
\text { decision aid or informed choice or person cent* or person focus* or patient cent* or patient } \\
\text { focus* or decision support or patient activation or shar* model or patient preference or } \\
\text { patient activation or decision theory or patient relation or professional-patient relations or } \\
\text { physician-patient relations or doctor-patient relations or patient involv* or participation) ) } \\
\text { AND ( (child* or adolesc* or young or youth or teen*) ) AND ( (mental health or mental } \\
\text { health service or mental illness or mental disorder or mental difficult* or mentally ill or } \\
\text { psychiatr*) ) AND ( (qualitative or ethnograph* or phenomenolog* or content analysis or } \\
\text { thematic analysis or constant comparative method or interview or focus group or case study } \\
\text { or grounded theory or narrative or interpretive phenomenological)) English Language; } \\
\text { Exclude MEDLINE records }\end{array}$ \\
\hline
\end{tabular}


Appendix 1 (continued)

Supplementary Table 1.

Continued.

Database Timespan Number of hits Search terms

Web of Science

All years

3981

(TS=((collaborati* or consultation* or cooperation or involvement or partnership or shar*

decision or decision making or SDM or information sharing or patient participation or decision aid or informed choice or person cent* or person focus* or patient cent* or patient focus* or decision support or patient activation or shar* model or patient preference or patient activation or decision theory or patient relation or professional-patient relations or physician-patient relations or doctor-patient relations or patient involv* or participation) AND (child* or adolesc* or young or youth or teen*) AND (mental health or mental health service or mental illness or mental disorder or mental difficult* or mentally ill or psychiatr*) AND (qualitative or ethnograph* or phenomenolog* or content analysis or thematic analysis or constant comparative method or interview or focus group or case study or grounded theory or narrative or interpretive phenomenological))) AND LANGUAGE: (English) AND DOCUMENT TYPES: (Article)

Note. "ti" = titles; "ab" = abstracts; "sh" = subject headings; "kw" = key words; "md" = methodology; "TS" = titles. 
Appendix 2

Supplementary Table 2.

Reasons for exclusion of full-texts.

Duplicates

Poster presentation (unpublished findings)

Not empirical study (e.g., editorial, commentary)

Not qualitative design

Does not elaborate on person-centered care

Adult population

Non-mental health setting (e.g. physical health, schools)

Does not elaborate barriers and/or facilitators to person-centered care 
Appendix 3

Supplementary Table 3

Quality assessment of how the studies were reported according to the CASP tool.

\begin{tabular}{|c|c|c|c|c|c|}
\hline \multicolumn{3}{|c|}{ Screening Question } & Answer & \multicolumn{2}{|l|}{ Study } \\
\hline \multirow{3}{*}{\multicolumn{3}{|c|}{$\begin{array}{l}\text { Was there a clear statement of the aims of the } \\
\text { research? }\end{array}$}} & Yes & \multirow{3}{*}{\multicolumn{2}{|c|}{$1-23$}} \\
\hline & & & No & & \\
\hline & & & Can`t tell & & \\
\hline \multirow{3}{*}{\multicolumn{3}{|c|}{ Is a qualitative methodology appropriate? }} & Yes & \multicolumn{2}{|c|}{$1-13,15-23$} \\
\hline & & & No & & \\
\hline & & & Can`t tell & \multicolumn{2}{|l|}{14} \\
\hline \multirow{3}{*}{\multicolumn{3}{|c|}{$\begin{array}{l}\text { Was the research design appropriate to address the } \\
\text { aims of the research? }\end{array}$}} & Yes & \multirow{3}{*}{\multicolumn{2}{|c|}{$\begin{array}{l}1-7,9,10,12-13,15-20,22-23 \\
11 \\
8,14,21\end{array}$}} \\
\hline & & & No & & \\
\hline & & & Can't tell & & \\
\hline \multirow{3}{*}{\multicolumn{3}{|c|}{$\begin{array}{l}\text { Was the recruitment strategy appropriate to the } \\
\text { aims of the research? }\end{array}$}} & Yes & \multicolumn{2}{|c|}{$1-10,16-20,22-23$} \\
\hline & & & No & & \\
\hline & & & Can`t tell & \multicolumn{2}{|c|}{$11-15,21$} \\
\hline \multirow{3}{*}{\multicolumn{3}{|c|}{$\begin{array}{l}\text { Was the data collected in a way that addressed the } \\
\text { research issue? }\end{array}$}} & Yes & \multicolumn{2}{|c|}{$1-10,13,15-20,22-23$} \\
\hline & & & No & \multicolumn{2}{|c|}{11} \\
\hline & & & Can`t tell & \multicolumn{2}{|c|}{$12,14,21$} \\
\hline \multirow{3}{*}{\multicolumn{3}{|c|}{$\begin{array}{l}\text { Has the relationship between researcher and } \\
\text { participants been adequately considered? }\end{array}$}} & Yes & \multirow{2}{*}{\multicolumn{2}{|c|}{$1,3-5,9,13,18-20$}} \\
\hline & & & No & & \\
\hline & & & Can't tell & \multicolumn{2}{|c|}{$2,6-8,10-12,14-17,21-23$} \\
\hline \multirow{3}{*}{\multicolumn{3}{|c|}{ Have ethical issues been taken into consideration? }} & Yes & \multicolumn{2}{|c|}{$2-6,7-11,15-22$} \\
\hline & & & No & \multirow{2}{*}{\multicolumn{2}{|c|}{$1,12,14,23$}} \\
\hline & & & Can`t tell & & \\
\hline \multirow{3}{*}{\multicolumn{3}{|c|}{ Was the data analysis sufficiently rigorous? }} & Yes & \multicolumn{2}{|c|}{$1-6,13,15-20,22-23$} \\
\hline & & & No & & \\
\hline & & & Can`t tell & $7,12,14$ & \\
\hline & & & Yes & $1-13,15$ & \\
\hline Is there a cle & r statement of fin & lings? & No & 14 & \\
\hline & & & Can`t tell & & \\
\hline & & Issues to consider & & & Discussed by \\
\hline & & Contribution to rese & rch/knowled & ge/policy & $1-13,15-20,22-23$ \\
\hline How valuabl & is the research? & Identification of nev & areas of res & earch & $\begin{array}{l}1,3-6,8-10,12-13 \\
15-17,19-20,22-23\end{array}$ \\
\hline & & Generalisability to o & her populati & ons & $\begin{array}{l}1,5-9,11-12,16 \\
18-20,22-23\end{array}$ \\
\hline No. of study & Reference & & of study & Referenc & \\
\hline 1 & Abrines-Jaume e & al. (2014) & & Ma \& Lai & 014) \\
\hline 2 & Buckley et al. (20 & 2) & & Moleswc & \& Crome (2011) \\
\hline 3 & Bury et al. (2007 & 15 & & Offord e & (2006) \\
\hline 4 & Coyne et al. (201 & 16 & & Oruche $\epsilon$ & I. (2014) \\
\hline 5 & Grealish et al. (2 & 11) & & Pelto-Pir & tal. (2013) \\
\hline 6 & Harper et al. (20 & 18 & & Pycroft e & I. (2013) \\
\hline 7 & Hart et al. (2005) & 19 & & Simmons & al. (2011) \\
\hline 8 & lachini et al. (201 & 20 & & Simmons & al. (2013) \\
\hline 9 & Idenfors et al. (2 & 15) & & Street (2 & \\
\hline 10 & Kovshoff et al. (2 & 12) & & Tam-Set & Versnel (2015) \\
\hline 11 & Lee et al. (2006) & 23 & & Wisdom & al. (2006) \\
\hline 12 & LeFrancois (2008 & & & & \\
\hline
\end{tabular}

